From the American

Board of Family Medicine

Ann Fam Med 2017;15:287-288. https://doi.org/10.1370/afm.2080

\section{IMPROVING PERFORMANCE IMPROVEMENT}

Since 2005 The American Board of Family Medicine (ABFM) has provided Diplomates with quality improvement tools for meeting the continuing certification Performance in Practice requirement. These tools took the form of Performance in Practice Modules (PPMs) based on the Deming model for quality improvement. ${ }^{1}$ The ABFM focused on common disorders encountered frequently by family physicians: diabetes, hypertension, asthma, depression, coronary artery disease, and heart failure. The Board also created a "comprehensive" PPM that provided Diplomates with a broader set of measure options based on the Ambulatory Quality Alliance (AQA) Starter Set. ${ }^{2}$ Since inception of the PPMs, Diplomates have completed over 98,000 quality improvement activities (ABFM internal report accessed 2/20/2017, available on request.)

As Diplomates have gained experience and familiarity with quality improvement methodology, ABFM has received a growing number of requests for more flexible and varied options for meeting Performance in Practice Requirements. Additionally, with the development of the PRIME registry, ${ }^{3}$ ABFM needed a vehicle for accepting electronic clinical quality measures (eCQMs) for use in Diplomates' performance improvement activities as well other reporting needs (eg Physicians Quality Reporting System (PQRS), Merit-Based Incentive Payment System (MIPS)). ${ }^{4}$ Briefly, the PRIME registry system includes several components: an extraction tool that derives measures data directly from electronic health records; a data warehouse to store these data; and the registry itself that holds the eCQM's for support of performance improvement and reporting.

Now, enter ABFM's revised Performance Improvement Activity (PIA) platform! Working with our vendor, FigMD, ABFM has re-worked the existing PPM product to support a broader spectrum of quality domains. Additionally, we have incorporated instructional materials regarding quality improvement methods (another aspect of functionality requested by many Diplomates over the years!) We worked with consultants from Case Western Reserve to develop these materials, and have integrated them into the product to provide contextually appropriate guidance throughout.
The platform provides tools and resources for identifying performance gaps, developing and implementing quality improvement plans, and accomplishing the reporting needs described earlier. Although we designed the system to support direct population of quality data from PRIME, the system also supports manual data entry for those Diplomates who do not yet participate in the registry.

The PIA platform currently supports 45 eCQM's as defined in the Measures Codes that the Center for Medicare and Medicaid Services (CMS) maintains for PQRS reporting. ${ }^{5}$ Additionally, ABFM physician staff have identified and vetted (for validity and freedom from commercial influence), for each measure, examples of web-based resources for implementing improvement plans. The platform organizes these resources by the categories included in the Chronic Care Model: clinical information systems, decision support, delivery system design, self-management support, and community resources and policies. ${ }^{6}$

Upon entering the system, Diplomates will see a dashboard that displays their performance on the 45 measures compared to their peers. Diplomates select the measures for which they wish to create a performance improvement project, and develop an intervention plan using the Chronic Care Model-based resources provided (or custom actions that the Diplomates develop locally.) (Supplemental Figures 1 \& 2 at http://www.annfammed.org/content/15/3/287/suppl/ DC1).

FigMD and ABFM development staff anticipate deployment in late second quarter or early third quarter 2017.

Additionally, ABFM has contracted with collaborators at the University of Missouri-Columbia to create a population health assessment tool (PHAsT) that will mate with the PIA platform. ${ }^{7}$ This functionality will facilitate Diplomates' ability to assess social determinants of health in their patient populations and how these parameters impact their quality improvement efforts.

At the time of this writing, we don't have access to screenshots for PHAsT display, as the system remains in development.

The ABFM developed and deployed the PPMs as a basic "baby step" to introduce Diplomates to quality improvement concepts and methods. We anticipated that family physicians and their organizations would develop increasing knowledge of and facility with quality improvement methodology over the years, and that PIA platform could likewise evolve to support these more sophisticated efforts. The ABFM anticipates that the new platform will indeed meet this expectation! 


\section{References}

1. Hunter J. The History and Evolution of the PDSA Cycle. May 28, 2015. https://blog.deming.org/2015/05/the-history-and-evolution-of-thepdsa-cycle/. Accessed Mar 8, 2017.

2. Agency for Healthcare Research and Quality. The Ambulatory Care Quality Alliance Recommended Starter Set. [Web page] 2005. https:// archive.ahrq.gov/professionals/quality-patient-safety/quality-resources/ tools/ambulatory-care/starter-set.html. Accessed Mar 8, 2017.

3. Phillips R. Reducing Burden, ensuring competence, improving quality, and enhancing professionalism: how can ABFM contribute to all? Ann Fam Med. 2016;14(4):387-388.

4. The Merit-Based Incentive Payment System. 2016. https://www.cms. gov/Medicare/Quality-Initiatives-Patient-Assessment-Instruments/ Value-Based-Programs/MACRA-MIPS-and-APMs/Quality-PaymentProgram-MIPS-NPRM-Slides.pdf. Accessed Mar 8, 2017.

5. Measures Codes Physician Quality Reporting System 2/01/2017. https://www.cms.gov/medicare/quality-initiatives-patient-assessmentinstruments/pqrs/measurescodes.html. Accessed Mar 8, 2017.

6. The Chronic Care Model. 2017. http://www.improvingchroniccare.org/ index.php?p=The_Chronic_CareModelEs=2. Accessed Mar 8, 2017.

7. Puffer JC. Board news: a message from the President. J Am Board Fam Med. 2017;30(2):266-267.

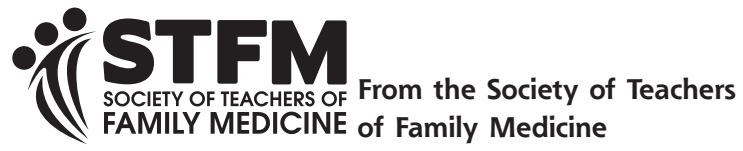

Ann Fam Med 2017;15:288-289. https://doi.org/10.1370/afm.2085.

\section{NEW CERTIFICATE PROGRAM PROVIDES FOUNDATIONAL TRAINING FOR RESIDENCY FACULTY}

STFM has launched an online certificate program to provide foundational training for residency faculty. Completion of the program requires approximately a 25-hour time commitment from participants, as well as a nominal time commitment from the participant's program director and colleagues. The program covers:

- The structure and requirements of residency education

- How to be an effective and efficient faculty member

- The nuts and bolts of curriculum development and teaching

- Strategies for assessment, feedback, and remediation of residents

Objectives related to training faculty are woven throughout STFM's strategic plan, the Family Medicine for America's Health (FMAHealth) strategic plan, and STFM's Faculty for Tomorrow initiative. In a 2013 STFM member survey, $70 \%$ of respondents expressed "some need" or "great need" for both online faculty development and resources for recruiting, training, and retaining faculty. The ACGME Program Requirements for Graduate Medical Education in Family Medicine state "There must be a structured program of faculty development that involves regularly scheduled faculty development activities designed to enhance the effectiveness of teaching, administration, leadership, scholarship, clinical, and behavioral components of faculty members' performance."

The overall goals for Residency Faculty Fundamentals are to:

- Provide longitudinal training for new residency faculty

- Provide training to improve or enhance fundamental knowledge, skills, attitudes, and/or abilities needed to be a family medicine faculty member

Each course has individual learning objectives. Topics include:

- ACGME Program Requirements

- Competencies, Milestones, and EPAs

- Structure and Funding of Residency Programs

- Billing and Documentation Requirements

- Recruiting and Interviewing Residents

- ABFM Rules and Requirements

- Scholarly Activity for Residency Faculty

- Writing for Academic Publication

- Curriculum Development

- Didactic Teaching Skills

- Clinical Teaching Skills

- Assessment and Evaluation

- Feedback

- Residents in Difficulty: Academic and Behavioral Problems

Courses include readings, videos, interactive modules, quizzes, and assignments. Some assignments require a significant time investment, including curriculum development, scholarly activity, and practicing feedback. A course instructor provides feedback on many of the assignments.

To graduate from the program, participants must complete all courses and assignments and pass a final exam within a 1-year timeframe. Those who graduate receive the certificate, up to 25 hours of CME credit (Application for CME credit has been filed with the American Academy of Family Physicians. Determination of credit is pending as of the writing of this article), a letter of congratulations noting the accomplishment, a letter to the graduate's program director, and a press release to distribute locally.

The Residency Faculty Fundamentals Certificate Program was developed by the STFM Graduate Medical Education (GME) Committee, STFM staff, and subject matter experts over past 2 years. Input was also garnered from focus groups and the STFM Board of Directors. "This was a huge undertaking that members and staff have immersed themselves in over the last couple of years," said Russell Maier, MD, chair of 